\title{
Diabetes and Thyroid Cancer Risk in the National Institutes of Health-AARP Diet and Health Study
}

\author{
Briseis Aschebrook-Kilfoy, ${ }_{1}^{1}$ Mona M. Sabra, ${ }^{2}$ Alina Brenner, ${ }^{3}$ Steven C. Moore, ${ }^{4}$ \\ Elaine Ron, ${ }^{3}$ Arthur Schatzkin, ${ }^{4}$ Albert Hollenbeck, ${ }^{5}$ and Mary H. Ward ${ }^{1}$
}

Background: We hypothesized that diabetes may play a role in thyroid cancer risk due to the parallel secular rise in diabetes prevalence and morbidity in the United States, the higher prevalence of thyroid disorders among diabetics compared with the general population, and the potential roles of metabolic syndrome, obesity, and diabetes as precipitating factors in cancer development.

Methods: We assessed the association between self-reported diabetes and the risk of differentiated thyroid cancer in the NIH-AARP Diet and Health Study, a prospective cohort of 200,556 women and 295,992 men, 50-71 years of age, in 1995-1996. Diabetes status and information on potential confounders was ascertained using a self-administered questionnaire. During an average of 10 years of follow-up, 585 thyroid cancer cases were identified. Cox proportional hazards models were used to estimate hazard ratios (HR) and 95\% confidence intervals (CI) for thyroid cancer and thyroid cancer subtypes in men and women according to diabetes status. Results: Nine percent of the total baseline cohort reported a history of diabetes ( $7 \%$ of women, $10 \%$ of men). A nonsignificant $25 \%$ increase in thyroid cancer risk ( $\mathrm{HR}=1.25$; 95\% CI: $0.95-1.64$ ) was associated with diabetes. Among women, the risk was significantly increased (HR $=1.46,95 \% \mathrm{CI}: 1.01-2.10)$. The risk was not elevated among men (HR $=1.04,95 \% \mathrm{CI}$ : 0.69-1.58). In this cohort, diabetic women with differentiated thyroid cancer were at somewhat higher risk of follicular thyroid cancer $(\mathrm{HR}=1.92 ; 95 \% \mathrm{CI}$ : 0.86-4.27) than papillary thyroid cancer (HR $=1.25$; 95\% CI: 0.80-1.97).

Conclusion: This study lends support to the hypothesis that diabetes increases the risk of differentiated thyroid cancer.

\section{Introduction}

D URING THE PAST SEVERAL DECADES, an increasing incidence of thyroid cancer has been observed in several countries, including the United States $(1,2)$, although the factors responsible for this rapid increase remain largely unknown (1). Certainly, increased prevalence of earlystaged thyroid cancer can be partly attributed to enhanced detection and increased use of neck ultrasounds and ultrasound-guided fine needle aspiration biopsies in the management of thyroid nodules. Nevertheless, it cannot explain the rise in disease prevalence preceding the widespread use of ultrasounds in clinical settings (3) and increased prevalence of large thyroid tumors $(>5 \mathrm{~cm})$, suggesting that other contributing factors may be involved (4). A parallel secular rise in diabetes prevalence and morbidity in the United States (5), a higher prevalence of thyroid disorders among diabetics compared with the general population $(10.8 \%$ in diabetics compared with $6.6 \%$ in the U.S. population) (6), and the potential roles of metabolic syndrome, obesity, and diabetes as precipitating factors in cancer development suggest that diabetes may play a role in thyroid cancer risk (7-13).

Plausible biologic pathways linking diabetes to thyroid cancer risk include (i) chronic thyroid-stimulating hormone (TSH) stimulation, a known thyroid cancer risk factor, in diabetics who are susceptible to disruption in thyroid hormone homeostasis (14-20); (ii) elevated circulating

\footnotetext{
${ }^{1}$ Occupational and Environmental Epidemiology Branch, ${ }^{3}$ Radiation Epidemiology Branch, and ${ }^{4}$ Nutrition Epidemiology Branch, Division of Cancer Epidemiology and Genetics, National Cancer Institute, National Institutes of Health, Department of Health and Human Services, Rockville, Maryland.

${ }^{2}$ Endocrine Service, Department of Medicine, Memorial Sloan-Kettering Cancer Center, New York, New York.

${ }^{5}$ Research and Strategic Analysis, AARP, Washington, District of Columbia.
} 
insulin levels in type 2 diabetics (T2D) with insulin resistance (21); (iii) antidiabetic medication-mediated effect, either through chronic exposure of elevated circulating insulin levels or through inherent drug or drug class characteristics (e.g., Glargine [Lantus], GLP-1 agonists [Amylin (Byetta)], and Liraglutide [Victoza]) (22); (iv) concomitant increased body mass index (BMI) in the majority of diabetics, which has been associated with increased risk for malignancies in general, and thyroid cancer in particular (23-25); (v) chronic glucose and triglyceride exposure, linked recently to increased thyroid cancer risk in Metabolic Syndrome and Cancer Project (Me-Can) cohorts (8); (vi) elevated prevalence of vitamin D deficiency in diabetics, which, in epidemiological studies, is linked to increased cancer risk, although the mechanism is not yet elucidated $(26,27)$.

Although the relationship between thyroid cancer and diabetes has been described in both case-control and cohort studies (28-39), small case numbers may have resulted in limited statistical power to detect an effect. To our knowledge, a limited number of studies have reported a statistically significant association between differentiated thyroid cancer risk and diabetes, though there have been reports of both nonsignificant positive and negative associations. In addition, previous analyses have not been stratified by histological type, which may be important as some evidence suggests that etiologic risk factors differ for papillary and follicular thyroid cancer, the two main types (40). The present study examines self-reported history of diabetes in relation to thyroid cancer risk and its variation by histologic type and gender, in the National Institutes of Health (NIH)-AARP Diet and Health Study, a large prospective cohort of men and women.

\section{Methods}

\section{Study population}

The NIH-AARP Diet and Health Study was initiated in 1995-1996 when a baseline questionnaire was mailed to 3.5 million AARP members, aged 50-71 years, residing in six U.S. states (California, Florida, Pennsylvania, New Jersey, North Carolina, and Louisiana) and two U.S. metropolitan areas (Atlanta, Georgia, and Detroit, Michigan) (41). The baseline questionnaire elicited information on usual dietary intake over the past 12 months, use of individual and multivitamin supplements, smoking history, alcohol intake, height and weight at baseline, other diet and lifestyle factors, and history of several personal and family medical conditions. A total of 617,119 persons $(17.6 \%)$ returned the questionnaire, and 567,169 questionnaires were determined to have been satisfactorily completed.

We excluded those with duplicate questionnaires, those who had died or moved out of the study area before baseline, those who withdrew from the study, those who had questionnaires completed by proxy respondents, and those who had been previously found to have cancer except for nonmelanoma skin cancer. After these exclusions, data for 496,548, including 295,992 men and 200,556 women, were available for the analysis.

The NIH-AARP Diet and Health Study was approved by the Special Studies Institutional Review Board of the National Cancer Institute.

\section{Cancer ascertainment}

Incident, first primary thyroid cancer cases (International Classification of Diseases for Oncology, Third Edition [ICD-O-3]) (42), topography code C73 were identified through December 31,2006 , via linkage of the cohort database to cancer registries of the eight original plus three additional states (Texas, Nevada, and Arizona). Thyroid cancers were classified as papillary (ICD-O-3 morphology codes 8050, 8660, 8340, 8341, 8343,8344 , and 8350) or follicular (ICD-O-3 morphology codes $8290,8330,8331,8332$, and 8335) type. The state cancer registries are certified by the North American Association of Central Cancer Registries as meeting the highest standard of quality (43).

\section{Diabetes status}

The medical history section of the baseline questionnaire asked about whether the study participant had ever been told by a doctor that he/she has diabetes. The question did not distinguish between type I diabetes (T1D) and T2D, and information about intake of diabetes medication was not collected. Among those included in our analysis, there were a total of 44,693 diabetics (14,766 women and 29,925 men). We did not have biochemical panels on self-reported diabetic subjects, including glucose, insulin, lipid, and $\mathrm{HbA} 1 \mathrm{c}$ levels. Thus, in this study, we could not correlate thyroid cancer risk in diabetics with glucose control.

\section{Statistical analysis}

Person-years of follow-up for each participant accrued from the date of return of the baseline questionnaire to the date of thyroid cancer diagnosis, the date of moving out of the cancer registry ascertainment area, death, or the end of the follow-up period, December 31, 2006. Cox proportional hazards models with person-years as the underlying time metric were used to estimate hazard ratios (HR) and 95\% confidence intervals $(\mathrm{CI})$. The proportional hazards assumption was tested and upheld in all analyses. We present HR estimates adjusted for age and sex, as well as those from the full model with and without BMI adjustment. The full model included attained age, smoking status (never, current, former), selfreported race/ethnicity (White, Black, other), family history of any cancer (yes, no), education, and BMI, which we divided into 10 categories $(16.0-18.4,18.5-20.9,21.0-23.4,23.5-24.9$, $25.0-26.4,26.5-27.9,28.0-29.9,30.0-34.9,35.0-39.9$, and 40.0 or more, $\mathrm{kg} / \mathrm{m}^{2}$ ). The inclusion of vitamin $\mathrm{D}$ in the model did not result in a change and information on TSH was not available in this cohort.

We also conducted interaction analyses between diabetes and gender, median age, BMI, and educational level. We assessed multiplicative interaction by adding the relevant crossproduct term to main-effects models. For all comparisons, $p$-values were two-sided and an alpha level of $<0.05$ indicated statistical significance.

\section{Results}

Of the 496,548 participants in our baseline analysis, $7.4 \%$ of female participants and $10.1 \%$ of male participants reported that a doctor had told them they had diabetes (Table 1). This is commensurate with CDC age-corrected diabetes prevalence in the general U.S. population (5). In this study population, 
Table 1. Means and Proportions for Baseline Characteristics of the National Institutes of Health-AARP Diet and Health Study Baseline Cohort by Diabetes Status

\begin{tabular}{|c|c|c|c|}
\hline Parameter & No diabetes & Diabetes & $\mathrm{p}$-Values \\
\hline Total $(N=496,548)$ & 451,885 & 44,693 & \\
\hline Age (mean) & 61.9 & 62.9 & $<0.01$ \\
\hline \multicolumn{4}{|l|}{ Race $(\%)$} \\
\hline White & 91.6 & 85.7 & \\
\hline Black & 3.6 & 7.5 & \\
\hline Other & 3.4 & 5.1 & $<0.01$ \\
\hline Never smoker $(\%)$ & 35.5 & 30.8 & $<0.01$ \\
\hline Education, college graduate or post graduate (\%) & 39.2 & 30.8 & $<0.01$ \\
\hline Vigorous physical activity, > five times per week (\%) & 19.5 & 16.0 & $<0.01$ \\
\hline Energy $(\mathrm{kcal} / \mathrm{d})$ & $1869(990)$ & $1883(1017)$ & \\
\hline BMI [Mean (SD)] & $26.8(4.9)$ & $29.9(6.0)$ & $<0.01$ \\
\hline Family history of cancer (\%yes) & 46.1 & 47.6 & $<0.01$ \\
\hline Women $(N=200,556)$ & 185,790 & 14,766 & \\
\hline Age (mean) & 61.8 & 62.7 & $<0.01$ \\
\hline \multicolumn{4}{|l|}{ Race $(\%)$} \\
\hline White & 89.8 & 80.6 & \\
\hline Black & 5.2 & 12.4 & \\
\hline Other & 3.4 & 4.7 & $<0.01$ \\
\hline Never smoker (\%) & 44.0 & 44.5 & 0.35 \\
\hline Education, college graduate or post graduate (\%) & 30.4 & 20.4 & $<0.01$ \\
\hline Vigorous physical activity, > five times per week (\%) & 16.5 & 11.7 & $<0.01$ \\
\hline Energy $(\mathrm{kcal} / \mathrm{d})$ & $1599(840)$ & $1660(975)$ & $<0.01$ \\
\hline BMI [Mean (SD)] & $26.5(5.8)$ & $31.3(7.1)$ & $<0.01$ \\
\hline Family history of cancer (\%yes) & 51.2 & 49.6 & $<0.01$ \\
\hline Men $(N=295,992)$ & 266,065 & 29,927 & \\
\hline Age (mean) & 62.0 & 63.0 & $<0.01$ \\
\hline \multicolumn{4}{|l|}{ Race $(\%)$} \\
\hline White & 92.8 & 88.2 & \\
\hline Black & 2.5 & 5.0 & \\
\hline Other & 3.5 & 5.2 & $<0.01$ \\
\hline Never smoker $(\%)$ & 29.7 & 24.0 & $<0.01$ \\
\hline Education, college graduate or post graduate $(\%)$ & 45.3 & 35.9 & $<0.01$ \\
\hline Vigorous physical activity, > five times per week (\%) & 21.6 & 18.2 & $<0.01$ \\
\hline Energy $(\mathrm{kcal} / \mathrm{d})$ & $2057(1042)$ & $1993(1020)$ & $<0.01$ \\
\hline BMI [Mean (SD)] & $27.1(4.2)$ & $29.2(5.2)$ & $<0.01$ \\
\hline Family history of cancer (\%yes) & 47.1 & 45.1 & $<0.01$ \\
\hline
\end{tabular}

BMI, body mass index; SD, standard deviation.

the absolute risk of thyroid cancer in female diabetics was $24.5 / 100,000$ woman-years and in male diabetics was 9.7/ 100,000 man-years. In non-diabetics, the absolute risk of thyroid cancer in females was 16.0/100,000 woman-years and in males was 8.8/100,000 man-years. A higher proportion of blacks and other race/ethnicity groups (Hispanic, Asian, Pacific Islander, and American Indian/Alaskan Native) were diabetic. In addition, diabetics reported lower levels of educational attainment, less vigorous physical activity, and a higher BMI. Also, diabetic men but not women tended to have a lower proportion of never smokers.

In the analysis cohort, there were 585 thyroid cancers (336 in females and 252 in males), including 412 papillary and 113 follicular type tumors. Overall, we observed no significant association for men and women combined (Table 2). However, when we evaluated thyroid cancer risk separately for men and women, we found different HR although the interaction by gender was not significant ( $p$ for heterogeneity $=0.35$ ). Among women with diabetes, risk of thyroid cancer was 1.46 times higher (95\% CI: 1.01-2.10) than that of women without diabetes, whereas the respective risk among men was close to one $(\mathrm{HR}=1.04 ; 95 \% \mathrm{CI}$ : 0.69-1.58). Thyroid cancer risk was increased for both the papillary $(\mathrm{HR}=1.23$; 95\% CI: 0.88-1.71) and follicular histologic types ( $\mathrm{HR}=1.36$; 0.75-2.46), though not significantly so. The differences in risk by gender for the papillary ( $p$ for heterogeneity $=0.40$ ) and follicular ( $p$ for heterogeneity $=0.89$ ) types were not significant. Among women, we found a HR of 1.25 for the papillary type (95\% CI: $0.80-1.97)$ and a HR of 1.92 for the follicular type (95\% CI: 0.86-4.27).

The risk of thyroid cancer associated with diabetes was similar among those at or above/below the median age of 62.6 years, at or above/below median BMI of $27 \mathrm{~kg} / \mathrm{m}^{2}$, and by education (high school or fewer years of education; some college or greater years of education) in the combined study population and women and men separately (not shown).

\section{Discussion}

In this large prospective cohort of AARP members, history of self-reported diabetes was associated with a $25 \%$ increase in thyroid cancer risk. This appeared to be primarily due to a 
Table 2. Self-Reported History of Diabetes and Risk of Thyroid Cancer by Histologic Type and Gender in the National Institutes of Health-AARP Diet and Health Study Baseline Cohort

\begin{tabular}{|c|c|c|c|c|c|c|}
\hline & \multicolumn{6}{|c|}{ Diabetes status and risk of thyroid cancer } \\
\hline & \multicolumn{2}{|c|}{ Total thyroid cancer } & \multicolumn{2}{|c|}{ Papillary } & \multicolumn{2}{|c|}{ Follicular } \\
\hline & No & Yes & No & Yes & No & Yes \\
\hline \multicolumn{7}{|l|}{ Overall } \\
\hline Number of cases & 525 & 60 & 371 & 41 & 100 & 13 \\
\hline Multivariate $\mathrm{HR}^{\mathrm{a}}$ & 1.00 & 1.32 & 1.00 & 1.31 & 1.00 & 1.42 \\
\hline $95 \%$ CI & (ref) & $1.01-1.73$ & & $0.95-1.81$ & & $0.80-2.54$ \\
\hline Multivariate $\mathrm{HR}^{\mathrm{b}}$ & 1.00 & 1.25 & 1.00 & 1.23 & 1.00 & 1.36 \\
\hline $95 \%$ CI & (ref) & $0.95-1.64$ & & $0.88-1.71$ & & $0.75-2.46$ \\
\hline \multicolumn{7}{|l|}{ Women } \\
\hline Number of cases & 302 & 34 & 226 & 22 & 49 & 7 \\
\hline Multivariate $\mathrm{HR}^{\mathrm{a}}$ & 1.00 & 1.54 & 1.00 & 1.35 & 1.00 & 1.93 \\
\hline $95 \%$ CI & (ref) & $1.08-2.20$ & & $0.87-2.10$ & & $0.85-4.71$ \\
\hline Multivariate $\mathrm{HR}^{\mathrm{b}}$ & 1.00 & 1.46 & 1.00 & 1.25 & 1.00 & 1.92 \\
\hline $95 \% \mathrm{CI}$ & (ref) & $1.01-2.10$ & & $0.80-1.97$ & & $0.86-4.27$ \\
\hline \multicolumn{7}{|l|}{ Men } \\
\hline Number of cases & 226 & 26 & 145 & 19 & 51 & 6 \\
\hline Multivariate $\mathrm{HR}^{\mathrm{a}}$ & 1.00 & 1.11 & 1.00 & 1.26 & 1.00 & 1.08 \\
\hline $95 \%$ CI & (ref) & $0.74-1.66$ & & $0.78-2.03$ & & $0.46-2.52$ \\
\hline Multivariate $\mathrm{HR}^{\mathrm{b}}$ & 1.00 & 1.04 & 1.00 & 1.18 & 1.00 & 1.01 \\
\hline $95 \%$ CI & (ref) & $0.69-1.58$ & & $0.73-1.93$ & & $0.43-2.39$ \\
\hline
\end{tabular}

${ }^{a}$ Adjusted for entry age and sex (overall).

${ }^{\mathrm{b}}$ Adjusted for age, sex (overall), smoking status, race/ethnicity, family history of cancer, BMI, and education.

$\mathrm{HR}$, hazard ratios; $\mathrm{CI}$, confidence interval.

$46 \%$ significantly increased risk of thyroid cancer among women, with only a slight change in risk observed among men. The finding of an elevated risk was observed for both papillary and follicular histologic types of thyroid cancer.

Although thyroid cancer typically occurs about three times more frequently in women than in men in the United States, rates of diabetes in men and women in the United States are similar $(1,5)$. Nonsignificant increases in risk in women have been observed in previous epidemiologic investigations of the association between thyroid cancer and diabetes $(31,36,37)$ as well as in men $(28,32,36,38)$, although the association between thyroid cancer and diabetes in general has been inconsistent. A study conducted by Meinhold et al. of U.S. Radiologic Technologists (24) reported a relative risk of 1.34 (95\% CI: 0.49-3.77) among women and no association among men (although only about $25 \%$ of the cohort are men). Similarly, Chodick et al. recently reported an increased risk of thyroid cancer in women $(\mathrm{HR}=1.61 ; 95 \% \mathrm{CI}: 0.96-2.69)$ but not men $(\mathrm{HR}=0.72 ; 95 \% \mathrm{CI}$ : 0.25-2.04) with T2D in an Israeli cohort (39).

There are a variety of possible biological mechanisms for the relationship between thyroid cancer and diabetes. Diabetics have a higher prevalence of thyroid disorders compared with the general population (10.81\% vs. 6.6\%) (6). Type 1 diabetics are prone to autoimmune thyroid disease, with up to $30 \%$ of women with T1D affected. As such, screening for thyroid dysfunction is recommended in this population (44). The association between T2D and subclinical hypothyroidism is also well recognized with reported prevalence in $2.2 \%-17 \%$ range (44). Although screening is not recommended, endocrinologists examining those patients are more prone to screen for thyroid dysfunction and nodularity than general practitioners, thus contributing to increased detection of thyroid cancer in this population. Furthermore, diabetics are more prone to mild, chronic TSH elevation, which, in recent studies, was demonstrated to be an independent risk factor for thyroid cancer development (15-20).

The association between thyroid cancer and diabetes risk may be due to variation in deiodinase expression in these disorders. Deiodinase enzymes regulate intracellular thyroid hormone levels, converting circulating prohormone T4 into its active form T3 (DIO1 or DIO2) or its inactive form rT3 (DIO3) $(45,46)$. Specifically, type 2 deiodinase regulates intracellular T3 concentration in the pituitary, brain, and brown fat (47). It is also expressed in skeletal muscle, where it indirectly regulates GLUT4 expression (48). As such, inactivation of DIO2 results in decreased intracellular T3 levels in skeletal muscle, which, in turn, would decrease GLUT4 transcription in skeletal muscle and adipose tissue, further contributing to insulin resistance. Similarly, inactivation of DIO2 results in decreased intracellular T3 levels in pituitary cells, which in turn stimulates TSH release $(45,46)$. DIO2 expression is modulated by a host of factors, including selenium and vitamin D3 levels, activation of Protein Kinase A, and Protein Kinase C pathways, and the presence of a DIO2 gene mutation (Thr92Ala variant). A recent metaanalysis of 11,033 participants found that subjects who had DIO2 Thr92Ala missense variation experienced increased T2D risk (49). Furthermore, DIO1 and DIO2 expression is reduced in papillary thyroid cancer $(50,51)$, whereas DIO2 expression is reported to be significantly increased in widely metastatic follicular thyroid carcinoma (52-54). Although the role of DIO1 and DIO2 in carcinogenesis is not known, studies have suggested that they play a role in tumor differentiation as opposed to de novo neoplastic transformation. In contrast, reactivation of DIO3 expression in tumoral cells with its ensuing intracellular hypothyroidism (low T3, elevated rT3) results in inhibition 
of thyroid hormone receptor-mediated suppression of ras-mediated transcription, proliferation, and transformation (55). This provides tumoral cells proliferation advantage as compared with neighboring normal cells.

In diabetics, chronic exposure to elevated circulating insulin levels is characteristic, from either endogenous (mediated by insulin resistance) or exogenous (chronic insulin therapy) sources. Insulin and insulin-like growth peptides share structural homology and affinity of its respective receptors (56). They are both important determinants of cell proliferation and apoptosis (56). Elevated circulating levels of insulin and insulin-like growth factor 1 are linked to increased risk of various cancers, including breast and colon (57-59). To date, there has been no association between insulin exposure and thyroid cancer in human studies. However, in laboratories, thyroid cancer cell lines are grown using a medium containing TSH, insulin, and cortisol, suggesting that insulin may play a role in thyroid carcinogenesis (60).

Chronic exposure to certain hypoglycemic agents used to treat patients with diabetes may also play a role in the complex relationship between diabetes and thyroid cancer incidence (22). Patients receiving metformin therapy (decreases insulin resistance) have a decreased risk of cancer and cancer mortality compared with those on insulin or sulfonylureas (increases insulin secretion) (22). Among insulin users (which typically includes all patients with T1D and some with T2D), those on Glargine (an insulin analog) may have an increased risk of cancer compared with those on human insulin, as suggested by a recently published observational study (22). The effect is believed to be mediated by increased and prolonged binding to the insulin-like growth factor 1-receptor leading to increased mitotic activity. To date, thyroid cancer has not been specifically implicated with prolonged sulfonylurea or insulin therapy. More recently, GLP-1 agonist therapy was linked with C-cell hyperplasia in humans and increased incidence of C-cell hyperplasias and medullary thyroid carcinoma in rodents. GLP-1 agonist does not appear to modulate differentiated thyroid cancer risk (22). The PPAR gamma agonist, Rosiglitazone (Avandia), was shown to induce apoptosis in PPAR gammapositive thyroid cancer cell lines and increases radioiodine uptake in dedifferentiated thyroid tumors (20).

Alternatively, increased thyroid cancer risk in diabetics may be accounted for by metabolic syndrome-related confounding variables, including abnormal glucose metabolism, triglyceride levels, and BMI. Obese subjects are at a 10-fold increased risk of developing diabetes (61), and obesity is also associated with increased risk of thyroid cancer including in this cohort (25). Obesity is thought to promote insulin resistance through the inappropriate inactivation of gluconeogenesis. In this study, detailed adjustment for BMI slightly reduces $(<10 \%)$ the risk of thyroid cancer, but did not explain the association between diabetes and thyroid cancer in women.

Recently, researchers from the Metabolic Syndrome and Cancer project linked glucose and triglyceride, independent of BMI, with increased risk of cancer (8). Specifically, an increased risk for thyroid cancer was observed for both men and women $(\mathrm{RR}=1.88 ; 95 \% \mathrm{CI}$ : $1.16-3.07$ and $\mathrm{RR}=0.72 ; 95 \% \mathrm{CI}$ : $0.47-1.10$, respectively) with $1 \mathrm{mmol} / \mathrm{L}$ blood glucose increments, though nonsignificant in women (8). Similarly, men were more prone to thyroid carcinoma with elevated triglycerides levels in the top studied quintile compared with bottom quintile (8).
Finally, vitamin D deficiency is hypothesized to account for lower incidence of cancer and cancer-related death in individuals living in southern latitudes compared with northern latitudes $(62,63)$. Vitamin D promotes differentiation and apoptosis of cancer cells in culture studies. Association of vitamin D therapy/sufficiency and risk of specific cancers (colon, breast, prostate, and pancreas) has yielded inconsistent results in observational studies $(64,65)$. To date, vitamin $\mathrm{D}$ deficiency, detected in up to $70 \%$ of diabetics, has not been associated with thyroid cancer risk. Low vitamin D levels decrease DIO2 expression (66), thus potentially linking diabetes to increased thyroid cancer risk.

The strengths of this study include its prospective design, completeness of follow-up, and the relatively large number of thyroid cancer cases with morphological diagnoses allowing for stratification by gender and histologic type. Limitations include the fact that we were unable to discriminate between T1D and T2D, and had no information on diabetes control, confounding variables such as TSH, lipid, and vitamin D levels, or diabetes medication. However, it seems that the proportion of subjects with T1D is likely to be small. The high proportion of non-Hispanic whites in our study population did not allow us to evaluate the effect of diabetes on thyroid cancer by race/ethnicity. As thyroid dysfunction is known to occur in diabetic patients and can contribute to significant metabolic disturbances, screening for thyroid abnormalities is not that uncommon (5), increasing the opportunity for incidental findings in the diabetic population. Unfortunately, we did not have data on the frequency of thyroid examinations in our study population. In sum, in the largest prospective evaluation to date, we found that thyroid cancer was significantly associated with diabetes among women. This study is also the first to present findings suggesting elevated risks for both the papillary and follicular types of thyroid cancer. As thyroid cancer is the sixth most common cancer among American women and the most common cancer of the endocrine system $(1,2)$, our findings warrant further evaluation.

\section{Acknowledgments}

This research was supported by the Intramural Research Program of the National Cancer Institute (NCI). The investigators are indebted to all participants for providing the data and for their commitment to the NIH-AARP Diet and Health Study.

\section{Disclosure Statement}

There are no financial or other interests with regard to the submitted article that might be construed as a conflict of interest.

\section{References}

1. Kilfoy BA, Devesa SS, Ward MH, Zhang Y, Rosenberg PS, Holford TR, Anderson WF 2009 Gender is an age-specific effect modifier for papillary cancers of the thyroid gland. Cancer Epidemiol Biomarkers Prev 18:1092-1100.

2. Kilfoy BA, Zheng T, Holford TR, Han X, Ward MH, Sjodin A, Zhang Y, Bai Y, Zhu C, Guo GL, Rothman N, Zhang Y 2009 International patterns and trends in thyroid cancer incidence, 1973-2002. Cancer Causes Control 20:525-531. 
3. Lew JI, Solorzano CC 2010 Use of ultrasound in the management of thyroid cancer. Oncologist 15:253-258.

4. Enewold L, Zhu K, Ron E, Marrogi AJ, Stojadinovic A, Peoples GE, Devesa SS. 2009 Cancer Epidemiol Biomarkers Prev 18:784-791.

5. Ahluwalia IB, Mack KA, Murphy W, Mokdad AH, Bales VS 2003 State-specific prevalence of selected chronic diseaserelated characteristics-behavioral risk factor surveillance system, 2001 MMWR Surveill Summ 52:1-80.

6. Wu P 2000 Thyroid disease and diabetes. Clin Diabetes 18:365-372.

7. Hsu IR, Kim SP, Kabir M, Bergman RN 2007 Metabolic syndrome, hyperinsulinemia, and cancer. Am J Clin Nutr 86:s867-s871.

8. Borena $W$, Stocks $T$, Jonsson $H$, Strohmaier S, Nagel G, Bjørge T, Manjer J, Hallmans G, Selmer R, Almquist M, Häggström C, Engeland A, Tretli S, Concin H, Strasak A, Stattin P, Ulmer H 2010 Serum triglycerides and cancer risk in the metabolic syndrome and cancer (Me-Can) collaborative study. Cancer Causes Control 22:291-299.

9. Gursoy A 2010 Rising thyroid cancer incidence in the world might be related to insulin resistance. Med Hypotheses 74:35-36.

10. Paes JE, Hua K, Nagy R, Kloos RT, Jarjoura D, Ringel MD 2010 The relationship between body mass index and thyroid cancer pathology features and outcomes: a clinicopathological cohort study. J Clin Endocrinol Metab 95:4244-4250.

11. Wolin KY, Carson K, Colditz GA 2010 Obesity Cancer Oncologist 15:556-565.

12. Potenaza M, Via MA, Yanagisawa RT 2009 Excess thyroid hormone and carbohydrate metabolism. Endocr Pract 15:254-262.

13. Udiong CE, Udoh AE, Etukudoh ME 2007 Evaluation of thyroid function in diabetes mellitus in Calabar, Nigeria. IJCB 22:74-78.

14. Hiasa Y, Kitahori Y, Kitamura M, Nishioka H, Yane K, Fukumoto M, Ohshima M, Nakaoka S, Nishii S 1991 Relationships between serum thyroid stimulating hormone levels and development of thyroid tumors in rats treated with N-bis-(2-hydroxypropyl)nitrosamine. Carcinogenesis 12:873-877.

15. Boelaert K 2009 The association between serum TSH concentration and thyroid cancer. Endocr Relat Cancer 16:10651072.

16. Haymart MR, Repplinger DJ, Leverson GE, Elson DF, Sippel RS, Jaume JC, Chen H 2008 A higher serum thyroid stimulating hormone level in thyroid nodule patients is associated with greater risks of differentiated thyroid cancer and advanced tumor stage. J Clin Endocrinol Metab 93:809-814.

17. Fiore E, Rago T, Provenzale MA, Scutari M, Ugolini C, Basolo F, Di Coscio G, Berti P, Grasso L, Elisei R, Pinchera A, Vitti P 2009 Lower levels of TSH are associated to a lower risk of papillary thyroid cancer in patients with thyroid nodular disease: thyroid autonomy may play a protective role. Endocr Relat Cancer 16:1251-1260.

18. Hovens GC, Stokkel MP, Kievit J, Corssmit EP, Pereira AM, Romijn JA, Smit JW 2007 Associations of serum thyrotropin concentrations with recurrence and death in differentiated thyroid cancer. J Clin Endocrinol Metab 92:2610-2615.

19. Jonklaas J, Nsouli-Maktabi H, Soldin SJ 2008 Endogenous thyrotropin and triiodothyronine concentrations in individuals with thyroid cancer. Thyroid 18:943-952.

20. Polyzos SA, Kita M, Efstathiadou Z, Poulakos P, Slavakis A, Sofianou D, Flaris N, Leontsini M, Kourtis A, Avramidis A
2008 Serum thyrotropin concentration as a biochemical predictor of thyroid malignancy in patients presenting with thyroid nodules. J Cancer Res Clin Oncol 134:953-960.

21. Vella V, Sciacca L, Pandini G, Mineo R, Squatrito S, Vigneri R, Belfiore A 2001 The IGF system in thyroid cancer: new concepts. Mol Pathol 54:121-124.

22. Smith U, Gale EA 2009 Does diabetes therapy influence the risk of cancer? Diabetologia 52:1699-1708.

23. Cléro E, Leux C, Brindel P, Truong T, Anger A, Teinturier C, Diallo I, Doyon F, Guénel P, de Vathaire F 2010 Pooled analysis of two case-control studies in New Caledonia and French Polynesia of body mass index and differentiated thyroid cancer: the importance of body surface area. Thyroid 20:1285-1293.

24. Meinhold CL, Ron E, Schonfeld SJ, Alexander BH, Freedman DM, Linet MS, Berrington de González A 2010 Nonradiation risk factors for thyroid cancer in the US Radiologic Technologists Study. Am J Epidemiol 171:242-252.

25. Leitzmann MF, Brenner A, Moore SC, Koebnick C, Park Y, Hollenbeck A, Schatzkin A, Ron E 2010 Prospective study of body mass index, physical activity and thyroid cancer. Int J Cancer 126:2947-2956.

26. Bener A, Alsaied A, Al-Ali M, Al-Kubaisi A, Basha B, Abraham A, Guiter G, Mian M 2009 High prevalence of vitamin D deficiency in type 1 diabetes mellitus and healthy children. Acta Diabetol 46:183-189.

27. Toner CD, Davis CD, Milner JA 2010 The vitamin D and cancer conundrum: aiming at a moving target. J Am Diet Assoc 110:1492-1500 (review).

28. LaVecchia C, Negri E, Franceschi S, Avanzo BD, Boyle P 1994 A case-control study of diabetes mellitus and cancer risk. Br J Cancer 70:950-953.

29. Mack WJ, Preston-Martin S, Bernstein L, Qian D 2002 Lifestyle and other risk factors for thyroid cancer in Los Angeles County females. Ann Epidemiol 12:395-401.

30. Zhan Y, Feng L, Tang S, Li WG, Xu M, Liu TF, ZhouYF, Ma YL, Zhang Y, Pu XM 2009 Glucose metabolism disorders in cancer patients in a Chinese population. Med Oncol 27:177184.

31. Inoue M, Iwasaki M, Otani T, Sasazuki S, Noda M, Tsugane S 2006 Diabetes mellitus and risk of cancer: results from a large-scale population-based cohort study in Japan. Arch Intern Med 166:1871-1877.

32. Kuriki K, Hirose K, Tajima K 2007 Diabetes and cancer risk for all and specific sites among Japanese men and women. Eur J of Cancer Prev 16:83-89.

33. Rousseau MC, Parent ME, Pollack MN, Siemiatycki J 2006 Diabetes mellitus and cancer risk in a population-based casecontrol study among men from Montreal, Canada. Int J Cancer 118:2105-2109.

34. Zivaljevic V, Vlajinac H, Jankovic R, Marinkovic J, Diklic A, Paunovic I 2004 Case-control study of anaplastic thyroid cancer. Tumori 94:9-12.

35. Zendehdel K, Nyren O, Ostenson CG,Adami H, Ekbom A, Ye W 2003 Cancer incidence in patientswith type 1 diabetes mellitus: a population-based cohort study in Sweden. J Natl Cancer Inst 95:1797-1800.

36. Wideroff L, Gridley, Mellemkjaer, Chow WH, Linet MS, Keehn S, Borch-Johnsen K, Olsen JH 1994 Cancer incidence in a population-based cohort of patients hospitalized with diabetes mellitus in Denmark. J Natl Cancer Inst 89:13601365.

37. Meinhold CL, Ron E, Schonfeld SJ, Alexander BH, Freedman DM, Linet MS, Berrington de Gonzalez A 2010 Nonradiation 
risk factors for thyroid cancer in the US Radiologic Technologists Study. Am J Epidemiol 171:242-252.

38. Adami HO, McLaughlin J, Ekbom A, Berne C, Silverman S, Hacker D, Persson I. 1991 Cancer risk in patients with diabetes-mellitus. Cancer Causes Control 2:307-314.

39. Chodick G, Heymann AD, Rosenmann L, Green MS, Flash S, Porath A, Kokia E, Shalev V 2010 Diabetes and risk of incident cancer: a large population-based cohort study in Israel. Cancer Causes Control 21:879-887.

40. Ron E, Schneider A 2006 Thyroid cancer. In: Schottenfeld D, Fraumeni JF Jr (eds) Cancer Epidemiology and Prevention, 3rd edition. Oxford University Press, New York, pp 975-994.

41. Schatzkin A, Subar AF, Thompson FE, Harlan LC, Tangrea J, Hollenbeck AR, Hurwitz PE, Coyle L, Schussler N, Michaud DS, Freedman LS, Brown CC, Midthune D, Kipnis V 2001 Design and serendipity in establishing a large cohort with wide dietary intake distributions: the National Institutes of Health-American Association of Retired Persons Diet and Health Study. Am J Epidemiol 154:1119-1125.

42. World Health Organization 2001 International Classification of Diseases for Oncology. World Health Organization, Geneva, Switzerland.

43. Michaud DS 2005 Comparison of cancer registry case ascertainment with SEER estimates and self-reporting in a subset of the NIH-AARP Diet and Health Study. J Registry Manage 32:70-75.

44. Hartl DM, Travagli JP 2009 The updated American thyroid association guidelines for management of thyroid nodules and differentiated thyroid cancer: a surgical perspective. Thyroid 1149-1151.

45. Köhrle J 2007 Thyroid hormone transporters in health and disease: advances in thyroid hormone deiodination. Best Pract Res Clin Endocrinol Metab 21:173-191.

46. Köhrle J 1999 Local activation and inactivation of thyroid hormones: the deiodinase family. Mol Cell Endocrinol 151:103-119.

47. Conn MP, Melmed S 1997 Endocrinology: Basic and Clinical Principles. Part V: Diseases and Systems. Iodothyronine Deiodination. Humana Press, Totowa, NJ.

48. St Germain DL, Galton VA 1997 The deiodinase family of selenoproteins. Thyroid 7:655-658.

49. Dora JM, Machado WE, Rheinheimer J, Crispim D, Maia AL 2010 Association of the type 2 deiodinase Thr92Ala polymorphism with type 2 diabetes: case-control study and meta-analysis. Eur J Endocrinol 163:427-434.

50. Arnaldi LA, Borra RC, Maciel RM, Cerutti JM 2005 Gene expression profiles reveal that $\mathrm{DCN}, \mathrm{DIO} 1$, and $\mathrm{DIO} 2$ are underexpressed in benign and malignant thyroid tumors. Thyroid 15:210-221.

51. Murakami M, Araki O, Hosoi Y, Kamiya Y, Morimura T, Ogiwara T, Mizuma H, Mori M 2001 Expression and regulation of type II iodothyronine deiodinase in human thyroid gland. Endocrinology 142:2961-2967.

52. De Souza Meyer EL, Dora JM, Wagner MS, Maia AL 2005 Decreased type 1 iodothyronine deiodinase expression might be an early and discrete event in thyroid cell dedifferentiation towards papillary carcinoma. Clin Endocrinol 62:672-678.

53. Kim BW, Daniels GH, Harrison BJ, Price A, Harney JW, Larsen PR, Weetman AP 2003 Overexpression of type 2 iodothyronine deiodinase in follicular carcinoma as a cause of low circulating free thyroxine levels. J Clin Endocrinol Metab 88:594-598.

54. Takano T, Miyauchi A, Ito Y, Amino N 2006 Thyroxine to triiodothyronine hyperconversion thyrotoxicosis in patients with large metastases of follicular thyroid carcinoma. Thyroid 16:615-618.

55. Dentice M, Ambrosio R, Salvatore D 2009 Role of type 3 deiodinase in cancer. Expert Opin Ther Targets 13:13631373.

56. Clemmons DR 1989 Structural and functional analysis of insulin-like growth factors Br Med Bull 45:465-480.

57. Hankinson SE, Willett WC, Colditz GA, Hunter DJ, Michaud DS, Deroo B, Rosner B, Speizer FE, Pollak M 1998 Circulating concentrations of insulin-like growth factor-I and risk of breast cancer. Lancet 351:1393-1396.

58. Peyrat JP, Bonneterre J, Hecquet B, Vennin P, Louchez MM, Fournier C, Lefebvre JDemaille A 1993 Plasma insulin-like growth factor-1 (IGF-1) concentrations in human breast cancer. Eur J Cancer 29:492-497.

59. Ma J, Pollak MN, Giovannucci E, Chan JM, Tao Y, Hennekens CH, Stampfer MJ 1999 Prospective study of colorectal cancer risk in men and plasma levels of insulin-like growth factor (IGF)-I and IGF-binding protein-3. J Natl Cancer Inst 91:620-625.

60. Paramesweran R, Brooks S, Sadler GP 2010 Molecular pathogenesis of follicular cell derived thyroid cancers. Int J Surg 8:186-193.

61. Marrero DG 2009 The Prevention of type 2 diabetes: an overview. J Diabetes Sci Technol 3:756-760.

62. Freedman DM, Looker AC, Abnet CC, Linet MS, Graubard BI 2010 Serum 25-hydroxyvitamin D and cancer mortality in the NHANES III study (1988-2006). Cancer Res 70:85878597.

63. Freedman DM, Looker AC, Chang SC, Graubard BI 2007 Prospective study of serum vitamin D and cancer mortality in the United States. Natl Cancer Inst 7:1594-1602.

64. Giovannucci E 2007 Epidemiological evidence for vitamin D and colorectal cancer. J Bone Miner Res 22 Suppl 2:V81-V85 (review).

65. Giovannucci E 2008Vitamin D status and cancer incidence and mortality. Adv Exp Med Biol 624:31-42 (review).

66. Macejová D, Ondková S, Brtko J 2009 Vitamin D(3) affects expression of thyroid hormone receptor alpha and deiodinase activity in liver of MNU-treated Sprague-Dawley rats. Gen Physiol Biophys 28:363-370.

Address correspondence to: Briseis Aschebrook-Kilfoy

Occupational and Environmental Epidemiology Branch Division of Cancer Epidemiology and Genetics National Cancer Institute

National Institutes of Health Department of Health and Human Services 6120 Executive Blvd, EPS 8111 Bethesda, MD 20892

E-mail: kilfoyb@mail.nih.gov 
